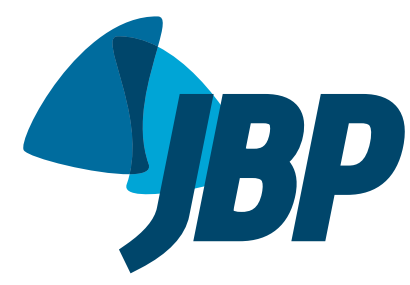

1. Escuela de Kinesiología, Universidad Santo Tomás, sede Viña del Mar, Viña del Mar, Chile.

2. Facultad de Ciencias, Pontificia Universidad Católica de Valparaíso, Valparaíso, Chile.

3. Escuela de Ciencias de la Salud Universidad Viña del Mar, Viña del Mar, Chile.

4. Carrera de Kinesiología, Unidad Docente Asociada de Ciencias de la Salud, Facultad de Medicina, Pontificia Universidad Católica de Chile, Santiago, Chile.

Submitted: 19 January 2015

Accepted: 8 May 2015.

Study carried out at the Escuela de Kinesiología, Universidad Santo Tomás, sede Viña del Mar, Viña del Mar, Chile.

\title{
Study of inhaler technique in asthma patients: differences between pediatric and adult patients
}

\author{
Pablo Manríquez ${ }^{1}$, Ana María Acuña² ${ }^{2}$ Luis Muñoz ${ }^{3}$, Alvaro Reyes ${ }^{4}$
}

\begin{abstract}
Objective: Inhaler technique comprises a set of procedures for drug delivery to the respiratory system. The oral inhalation of medications is the first-line treatment for lung diseases. Using the proper inhaler technique ensures sufficient drug deposition in the distal airways, optimizing therapeutic effects and reducing side effects. The purposes of this study were to assess inhaler technique in pediatric and adult patients with asthma; to determine the most common errors in each group of patients; and to compare the results between the two groups. Methods: This was a descriptive cross-sectional study. Using a ten-step protocol, we assessed inhaler technique in 135 pediatric asthma patients and 128 adult asthma patients. Results: The most common error among the pediatric patients was failing to execute a 10 -s breath-hold after inhalation, whereas the most common error among the adult patients was failing to exhale fully before using the inhaler. Conclusions: Pediatric asthma patients appear to perform most of the inhaler technique steps correctly. However, the same does not seem to be true for adult patients.

Keywords: Administration, inhalation; Aerosols/administration \& dosage; Asthma/ prevention \& control.
\end{abstract}

\section{INTRODUCTION}

Inhaler technique comprises a set of procedures for drug delivery to the respiratory system. The oral inhalation of medications is the first-line treatment for lung diseases, and metered-dose inhalers (MDIs) are one of the drug delivery systems most frequently used by patients. ${ }^{(1)}$ The use of oral medications offers many advantages, because these medications act directly on the airways and require administration of lower doses, with no gastric changes. ${ }^{(2)}$ Using the proper inhaler technique ensures sufficient deposition of drug particles in the distal airways, optimizing drug effectiveness and reducing possible side effects.

One of the determinants of the effectiveness of inhaled medications is the ability of the patient to adhere to good inhaler techniques. ${ }^{(3)}$ For some patients, that can be difficult, and the prescription of medication should therefore always be accompanied by appropriate inhaler technique training delivered by a health professional. Thus, it is possible to reduce the number of inhaler technique errors and minimize the clinical consequences of poor drug delivery.

The first therapeutic aerosol devices were developed in the $1950 \mathrm{~s}^{(4)}$ and consisted of nebulizers and atomizers containing anticholinergics for treatment of asthma. (5) Despite the long time since development and the wide use of these devices, inhaler technique errors continue to be common among respiratory patients, ${ }^{(6)}$ reducing the benefits of inhaled medications. In Chile, Solís et al. (7) observed that only $12.5 \%$ of the mothers of hospitalized infants have a correct inhaler technique. However, it is unknown whether this trend is reflected in adult patients, given that the elderly are more likely to make inhaler technique errors. ${ }^{(8)}$ This promotes the assessment of inhaler technique by age group, because tailoring education to the needs of each patient could significantly improve disease management. The purposes of the present study were to assess inhaler technique in pediatric and adult patients with asthma; to determine the most common errors in each group of patients; and to compare the results between the two groups.

\section{METHODS}

This was a descriptive cross-sectional study conducted in the region of Valparaíso, Chile, between March and May of 2014. The sample consisted of male and female patients with a diagnosis of asthma based on spirometry, in accordance with the Global Initiative for Asthma criteria. ${ }^{(9)}$ The ages of the participants ranged from 5 to 90 years, and the sampling was non-probabilistic (purposive). Patients had to meet the following inclusion criteria: being enrolled in and attending follow-up visits as part of an asthma program in clinics in the region of Valparaíso, regardless of smoking status; having received a prescription for a bronchodilator and having been instructed on the proper use of their inhaler (practical demonstration by a nurse, physician, or kinesiologist at each follow-up appointment); and being able to self-administer inhaled medication. We

Correspondence to:

Pablo Manríquez Villarroel.

Escuela de Kinesiología, Universidad Santo Tomás, sede Viña del Mar, Avenida Uno Norte 3041, 25200000, Viña del Mar, Chile.

Tel.: 560322448101

E-mail: pablomanriquez@santotomas.cl

Financial support: None. 
excluded patients who had a respiratory comorbidity or any concomitant condition that could directly affect inhaler technique (prostration, oxygen dependence, or altered cognitive status).

All participants gave written informed consent, and the study was approved by the Research Ethics Committee of the University of Santo Tomás at Viña del Mar School of Kinesiology.

For comparative purposes, the patients were divided into two groups: pediatric patients (5-18 years); and adult patients (19-90 years). The volunteers were recruited during their follow-up appointments at the health facilities. On that occasion, they were scheduled to undergo assessment one week later. On the assessment day, they were asked to use their inhaler as usual. All volunteers used their own valve spacer (appropriate to their age). They received no additional instruction, coaching, or correction during inhaler use. The medication administered was albuterol (100 $\mu$; Fesema $\Re$; Laboratorio ETEX, Santiago, Chile), used as rescue medication and delivered with an MDI.

Inhaler technique was assessed using a protocol described by Melani, ${ }^{(10)}$ as shown in Table 1 . This protocol documents the performance of ten essential inhaler technique steps by means of closed dichotomous response options (well performed/poorly performed). All assessments were made by two investigators with ten years of experience in the follow-up of asthma patients. After assessment, all patients were given supplemental instruction on inhaler technique by a health professional, in the form of a demonstration.

On the basis of a study of inhaler technique in pediatric patients, ${ }^{(11)}$ which reported an $89.1 \%$ completion rate for "hold breath for 10 seconds", we calculated that, in order to achieve an alpha of $5 \%$, a statistical power of $80 \%$, and an estimation error of $6 \%$, a sample size of at least 104 patients was required. Allowing for a loss of $10 \%$, we determined that the minimum sample size needed was 115 patients.

For data analysis, we used descriptive statistics, calculating the number of errors per patient and the percentage of completion for each step of the protocol. The results were tabulated and analyzed with Microsoft Excel 2010. Differences between the percentages of errors made by each group were determined by the equivalence test for two proportions. Values of $p<$ 0.05 were considered significant.

\section{RESULTS}

The total number of patients selected was 270 . We excluded seven patients, for the following reasons: prostration ( $n=2)$; oxygen-dependence $(n=2)$; Alzheimer's disease $(n=2)$; and sequelae of pulmonary tuberculosis $(n=1)$. The final sample therefore consisted of 263 patients: 135 pediatric patients and 128 adult patients. Of those, $44.1 \%$ were male. All patients had been diagnosed with bronchial asthma.
Table 1. Inhaler use protocol described by Melani. ${ }^{(10)}$

1. Remove the cap from the inhaler

2. Shake the inhaler before use

3. Exhale before using the inhaler

4. Insert the inhaler into the spacer

5. Hold the inhaler upright with the mouthpiece at the bottom during use

6. Take only one puff at a time

7. Actuate the inhaler in the first half of inhalation

8. Inhale slowly while actuating the inhaler

9. Continue to inhale after actuation

10. Hold breath for 10 seconds

The general characteristics of the participants are shown in Table 2. In the pediatric group, the most well-represented age group was the 13- to 18-year group, with 63 patients, whereas the 61- to 75-year group was predominant, with 51 patients, in the adult group.

Table 3 shows the types of errors made by the pediatric and adult patients. The most common errors in the pediatric group were failing to execute a $10-\mathrm{s}$ breath-hold after inhalation (in $8.1 \%$ ) and failing to continue to inhale after actuation (in $6.1 \%$ ). In the adult group, $53.1 \%$ failed to exhale before using the inhaler, whereas $46 \%$ failed to execute a 10 -s breathhold after inhalation.

Table 4 shows the frequency of correct and incorrect inhaler technique, by patient age group. In the 61- to 75- and 76- to 90-year age groups, the frequency of incorrect technique was greatest (48 and 35 patients, respectively). Significant differences were found in the frequency of incorrect technique between the pediatric and adult groups.

\section{DISCUSSION}

The results of the present study show that most of the pediatric patients used correct inhaler techniques. The most common errors were failing to execute a 10 -s breath-hold after inhalation (in $8.1 \%$ ) and failing to continue inhaling after actuation of the device (in $6.1 \%)$. Among the adult patients, the most common errors were failing to exhale before using the inhaler (in 53.1\%) and failing to execute a 10 -s breath-hold after inhalation (in $46 \%$ ). Crompton et al. ${ }^{(11)}$ stated that poor inhaler technique in older patients might be due to cognitive impairment and their inability to retain the instructions received from the medical team. It is important to point out that, although the protocol used in our study is a guide for correct inhaler technique in adult patients, we found that pediatric patients appear to have better inhaler technique.

These results are consistent with what was described by Flor et al. ${ }^{(12)}$ Studies of inhaler technique have established that the most common errors are, in order of incidence, as follows: poor coordination between actuation and inhalation; an insufficient breath-hold after inhalation; excessive inhalation flow; failing 
Table 2. General characteristics of the sample.

\begin{tabular}{|c|c|c|c|c|c|c|c|}
\hline \multicolumn{8}{|c|}{ Characteristic } \\
\hline \multirow[t]{2}{*}{ Age, years } & \multirow[t]{2}{*}{$\mathbf{n}^{\mathrm{a}}$} & \multirow{2}{*}{$\begin{array}{c}\text { Male gender, } \\
\%^{b}\end{array}$} & \multicolumn{4}{|c|}{ Mean ${ }^{c}$} & \multirow{2}{*}{$\begin{array}{c}\text { Tobacco } \\
\text { consumption, \% }\end{array}$} \\
\hline & & & Age, years & FEV $_{1}{ }^{d}$ & FVC $^{d}$ & $\mathrm{FEV}_{1} / \mathrm{FVC}^{\mathrm{d}}$ & \\
\hline \multicolumn{8}{|l|}{ Pediatric patients } \\
\hline $5-6$ & 8 & 87.5 & $6.0 \pm 0.5$ & $82 \pm 20$ & $100 \pm 9$ & $72 \pm 9$ & 0.0 \\
\hline $7-8$ & 13 & 76.9 & $7.0 \pm 0.5$ & $81 \pm 15$ & $98 \pm 8$ & $70 \pm 8$ & 0.0 \\
\hline $9-10$ & 21 & 47.6 & $9.0 \pm 0.5$ & $81 \pm 7$ & $99 \pm 7$ & $70 \pm 9$ & 0.0 \\
\hline $11-12$ & 30 & 50.0 & $12.0 \pm 0.5$ & $79 \pm 14$ & $99 \pm 10$ & $71 \pm 5$ & 0.0 \\
\hline $13-18$ & 63 & 47.6 & $14.0 \pm 0.5$ & $79 \pm 19$ & $101 \pm 8$ & $72 \pm 7$ & 30.0 \\
\hline \multicolumn{8}{|l|}{ Adult patients } \\
\hline $19-30$ & 12 & 58.3 & $23 \pm 0.7$ & $78 \pm 10$ & $101 \pm 18$ & $71 \pm 8$ & 25.0 \\
\hline $31-45$ & 6 & 50.0 & $34.0 \pm 0.6$ & $82 \pm 9$ & $102 \pm 15$ & $69 \pm 11$ & 33.3 \\
\hline $46-60$ & 25 & 48.0 & $51.0 \pm 0.6$ & $80 \pm 10$ & $99 \pm 19$ & $70 \pm 7$ & 28.0 \\
\hline $61-75$ & 51 & 49.0 & $67.0 \pm 0.7$ & $81 \pm 12$ & $98 \pm 18$ & $71 \pm 9$ & 29.4 \\
\hline $76-90$ & 34 & 52.9 & $79.0 \pm 0.5$ & $79 \pm 15$ & $95 \pm 15$ & $69 \pm 9$ & 14.7 \\
\hline Total & 263 & 100.0 & & & & & \\
\hline
\end{tabular}

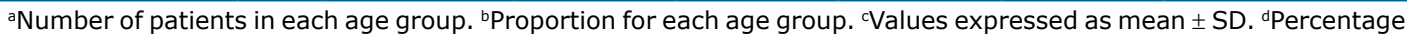
of predicted value.

Table 3. Frequency and percentages of inhaler technique errors observed in the pediatric and adult groups.

\begin{tabular}{|c|c|c|c|c|}
\hline \multirow[t]{2}{*}{ Type of error } & \multicolumn{2}{|c|}{ Pediatric group } & \multicolumn{2}{|c|}{ Adult group } \\
\hline & $\mathbf{n}^{\mathrm{a}}$ & $\%^{\mathrm{b}}$ & $n^{\mathrm{a}}$ & $\%^{\mathrm{b}}$ \\
\hline Failing to exhale before using the inhaler & 5 & 3.7 & 68 & 53.1 \\
\hline Failing to hold breath for $10 \mathrm{~s}$ & 11 & $8.1^{*}$ & 59 & $46.0^{*}$ \\
\hline Failing to take only 1 puff at a time & 4 & 3.0 & 37 & 28.0 \\
\hline Failing to continue to inhale after actuation of the inhaler & 8 & 6.1 & 35 & 26.5 \\
\hline Failing to actuate the inhaler in the first half of inhalation & 4 & 3.0 & 30 & 22.7 \\
\hline Failing to shake the inhaler before use & 0 & 0.0 & 25 & 18.9 \\
\hline Failing to inhale gently and deeply while actuating the inhaler & 4 & 3.0 & 14 & 10.6 \\
\hline Failing to insert the inhaler into the spacer & 1 & 0.7 & 11 & 8.6 \\
\hline Failing to hold the inhaler upright with the mouthpiece at the bottom during use & 0 & 0.0 & 2 & 1.5 \\
\hline
\end{tabular}

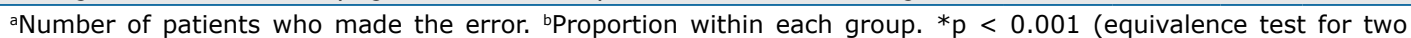
proportions).

to shake the canister vigorously before use; failing to continue to inhale after actuation; pressing the canister down several times during the course of a single inhalation; exhaling during actuation; and failing to hold the inhaler upright. ${ }^{(13)}$

Other authors have observed that the rate of inhaler technique errors decreases when devices other than MDIs are used. ${ }^{(14)}$ However, drug delivery effectiveness is similar when inhaler technique is correct, ${ }^{(15)}$ regardless of the device used.

Poor inhaler technique has clinical consequences ranging from minor to critical. ${ }^{(6,10)}$ Under this criterion, the results of our study allow us to state that the most frequent error made by the pediatric patients (made by 13 subjects) would moderately affect drug deposition in the lung, whereas the most frequent error made by the adult patients (made by 90 subjects) would slightly affect this deposition. As for specific consequences, the poor inhaler technique observed in the two groups of patients can affect drug delivery to the distal airways and prevent drug deposition on the respiratory epithelium. ${ }^{(16)}$ The clinical implication of these results is that, in patients with poor inhaler technique, there is a waste of inhaled medication. Consequently, there would be an increase in the economic costs associated with the disease, an increase in the risk of side effects, and a reduction in treatment effectiveness.

Respiratory patient education is a critical factor in the proper use of medications. ${ }^{(17)}$ Asthma patient education programs substantially improve adherence and inhaler technique. ${ }^{(18)}$ All participants in our investigation regularly attend their follow-up appointments, and, at each such opportunity, they are instructed in the proper use of their medications. Nevertheless, our results show that errors in inhaler use persist. These mistakes are considered either unintentional (patients not noticing that their inhaler technique is poor) or intentional (patients knowingly using the incorrect inhaler technique). ${ }^{(18)}$ In addition, there is clear evidence that inhalers are underused among asthma patients. ${ }^{(19)}$ In this aspect, one of the limitations of our study was that we did not delve into the causes of the observed errors, which would have made it possible to provide each patient with specific supplemental instruction on the proper administration of the medication.

In our sample, we found that approximately $30 \%$ of the adult patients were smokers. Although this proportion is lower than observed among adults in Chile 
Table 4. Frequency of correct/incorrect inhaler technique, by age group.

\begin{tabular}{ccc} 
Age (years) & $\begin{array}{c}\text { Correct } \\
\text { technique }\end{array}$ & $\begin{array}{c}\text { Incorrect } \\
\text { technique }\end{array}$ \\
$\begin{array}{c}\text { Pediatric } \\
\text { patients }\end{array}$ & $n$ & $n$ \\
$5-6$ & 5 & 3 \\
$7-8$ & 12 & 1 \\
$9-10$ & 14 & 7 \\
$11-12$ & 19 & 11 \\
$13-18$ & 49 & 14 \\
$\%$ & 73.4 & $26.6^{*}$ \\
Adult patients & & \\
$19-30$ & 9 & 3 \\
$31-45$ & 0 & 6 \\
$46-60$ & 1 & 24 \\
$61-75$ & 3 & 48 \\
$76-90$ & 1 & 35 \\
$\%$ & 9.4 & $90.6^{*}$ \\
\hline * & & \\
\hline 0.05 (equivalence test for two proportions)
\end{tabular}

$(40.6 \%),{ }^{(20)}$ it is significant, given that smoking affects asthma control. ${ }^{(21)}$ Therefore, tobacco consumption in these patients would further increase the difficulty in controlling the disease.

Recent studies suggest that better results would be obtained by tailoring inhaler prescription to suit the characteristics and functional capabilities of each patient. ${ }^{(22)}$ It has been observed that even individuals with correct inhaler technique can make errors if they are reassessed over time, ${ }^{(23)}$ which makes it mandatory to provide patients with ongoing education in the administration of inhaled medications. Many times there are factors that hinder this learning process, such as limited duration of appointments, a lack of knowledge on the part of health care personnel about the correct steps of the inhaler technique, and the technical language used in teaching the technique. ${ }^{(16)}$ Therefore, it is necessary to use new methods to provide patients with supplemental instruction on correct inhaler use, such as videos or illustrative leaflets that can promote the retention of information by patients. ${ }^{(24)}$ In addition, it is necessary that supplemental instruction on inhaler use protocols be properly provided to health personnel and included in asthma clinical guidelines, which rarely address the administration of inhaled medications. ${ }^{(25)}$

In conclusion, we found that most pediatric asthma patients appear to have correct inhaler technique. However, the same does not seem to be true for approximately $90 \%$ of adult patients, among whom the most common error was failing to exhale before using the inhaler. We suggest that asthma patients, especially those who are older, should be given supplemental instruction on inhaler technique through the use of new methods, so that they can administer their medications properly.

\section{REFERENCES}

1. Chorão P, Pereira AM, Fonseca JA. Inhaler devices in asthma and COPD-an assessment of inhaler technique and patient preferences. Respir Med. 2014;108(7):968-75. http://dx.doi.org/10.1016/j. rmed.2014.04.019

2. Aviña Ferro JA, Navarro Ibarra JE. Aerosolterapia mediante los nuevos inhaladores de dosis medida. Rev Fac Med UNAM. 2003;46(5):190-92

3. Giner J, Basualdo LV, Casan P, Hernández C, Macián V, Martínez I, et al. Guideline for the use of inhaled drugs. The Working Group of SEPAR: the Nursing Area of the Sociedad Española de Neumología y Cirugía Torácica [Article in Spanish]. Arch Bronconeumol. 2000;36(1):34-43. http://dx.doi.org/10.1016/S0300-2896(15)30231-3

4. Callard PE, Prokopovich P. History of inhaler devices. In: Prokopovich $P$, editor. Inhaler devices: Fundamentals, design and drug delivery Sawston, Cambridge, UK: Woodhead Publishing Limited; 2013. p. 13-27. http://dx.doi.org/10.1533/9780857098696.1.13

5. Cox Fuenzalida PP. Terapia Inhalatoria. Medwave [serial on the Internet]. 2008 Oct [cited 2014 Jun 22];8(10):e1791 [about 10p.] Available from: http://www.medwave.cl/link.cgi/Medwave/ Reuniones $/ 1791$ ?tab=metrica

6. Melani AS, Bonavia M, Cilenti V, Cinti C, Lodi M, Martucci P, et al Inhaler mishandling remains common in real life and is associated with reduced disease control. Respir Med. 2011;105(6):930-8. Erratum in: Respir Med. 2012 May;106(5):757. DelDonno, Mario [corrected to Del Donno, Mario]. http://dx.doi.org/10.1016/j. rmed.2011.01.005

7. Solís OY, Menchaca OG, Vega-Brice-o L, Cerda LJ. Evaluation of the inhalatory technique in hospitalized infants [Article in Spanish]. Rev Chil Pediatr. 2008;79(2):152-6.

8. Rance K, O'Laughlen M. Managing Asthma in Older Adults. J Nurse Pract. 2014;10(1):1-9. http://dx.doi.org/10.1016/j.nurpra.2013.11.009

9. Global Initiative for Asthma. Guía de bolsillo para el manejo y la prevención del asma. Bethesda: GINA; 2014. p. 1-32.

10. Melani AS. Inhalatory therapy training: a priority challenge for the physician. Acta Biomed. 2007;78(3):233-45.

11. Crompton GK, Barnes PJ, Broeders M, Corrigan C, Corbetta L, Dekhuijzen $R$, et al. The need to improve inhalation technique in Europe: a report from the Aerosol Drug Management Improvement Team. Respir Med. 2006;100(9):1479-94. http://dx.doi.org/10.1016/j. rmed.2006.01.008

12. Flor Escriche $X$, Rodríguez Mas M, Gallego Alvarez L, Alvarez Luque I, Juvanteny Gorgals J, Fraga Martínez MM, et al. Do our asthma patients still use inhalers incorrectly? [Article in Spanish] Aten Primaria. 2003;32(5):269-74. http://dx.doi.org/10.1016/S02126567(03)79273-7

13. Sociedad Española de Neumología y Cirugía Torácica-Asociación Latinoamericana del Tórax. Consenso SEPAR-ALAT sobre terapia inhalada. Arch Bronconeumol. 2013;49(Suppl.1):2-14. http://dx.doi. org/10.1016/S0300-2896(13)70068-1

14. Haughney J, Price D, Barnes NC, Virchow JC, Roche N, Chrystyn H. Choosing inhaler devices for people with asthma: current knowledge and outstanding research needs. Respir Med. 2010;104(9):1237-45. http://dx.doi.org/10.1016/j.rmed.2010.04.012

15. Dolovich MB, Dhand R. Aerosol drug delivery: developments in device design and clinical use. Lancet. 2011;377(9770):1032-45. http://dx.doi.org/10.1016/S0140-6736(10)60926-9

16. Fink JB, Rubin BK. Problems with inhaler use: a call for improved clinician and patient education. Respir Care. 2005;50(10):1360-74; discussion 1374-5

17. García-Cárdenas V, Sabater-Hernández D, Kenny P, Martínez Martínez F, Faus MJ, Benrimoj SI. Effect of a pharmacist intervention on asthma control. A cluster randomised trial. Respir Med. 2013;107(9):1346-55. http://dx.doi.org/10.1016/j.rmed.2013.05.014

18. Inhaler Error Steering Committee, Price D, Bosnic-Anticevich S, Briggs $\mathrm{A}$, Chrystyn $\mathrm{H}$, Rand $\mathrm{C}$, et al. Inhaler competence in asthma: common errors, barriers to use and recommended solutions. Respir Med. 2013;107(1):37-46. http://dx.doi.org/10.1016/j. rmed.2012.09.017 
19. Oliveira PD, Menezes AM, Bertoldi AD, Wehrmeister FC. Inhaler use in adolescents and adults with self-reported physician-diagnosed asthma, bronchitis, or emphysema in the city of Pelotas, Brazil. J Bras Pneumol. 2013;39(3):287-95. http://dx.doi.org/10.1590/S180637132013000300005

20. Ministerio de Salud [homepage on the Internet]. Santiago: El Ministerio. Encuesta Nacional de Salud ENS Chile 20092010. [cited 2014 Jun 22]. [Adobe Acrobat document, p. 152-88]. Available from: http://web.minsal.cl/portal/url/item/ bcb03d7bc28b64dfe040010165012d23.pdf

21. Haughney J, Price D, Kaplan A, Chrystyn H, Horne R, May N, et al. Achieving asthma control in practice: understanding the reasons for poor control. Respir Med. 2008;102(12):1681-93. http://dx.doi org/10.1016/j.rmed.2008.08.003

22. Dekhuijzen PN, Vincken W, Virchow JC, Roche N, Agusti A, Lavorini F, et al. Prescription of inhalers in asthma and COPD: towards a rational rapid and effective approach. Respir Med. 2013;107(12):1817-21. http://dx.doi.org/10.1016/j.rmed.2013.09.013

23. Virchow JC, Crompton GK, Dal Negro R, Pedersen S, Magnan A Seidenberg J, et al. Importance of inhaler devices in the management of airway disease. Respir Med. 2008;102(1):10-9. http://dx.doi. org/10.1016/j.rmed.2007.07.031

24. Wilson EA, Park DC, Curtis LM, Cameron KA, Clayman ML, Makou $G$, et al. Media and memory: the efficacy of video and print materials for promoting patient education about asthma. Patient Educ Couns. 2010;80(3):393-8. http://dx.doi.org/10.1016/..pec.2010.07.011

25. Dekhuijzen PN, Bjermer L, Lavorini F, Ninane V, Molimard M Haughney J. Guidance on handheld inhalers in asthma and COPD guidelines. Respir Med. 2014;108(5):694-700. http://dx.doi. org/10.1016/j.rmed.2014.02.013 